\title{
Recurrence of Primary Pulmonary Hydatidosis in the Left Lung with No Hepatic Involvement
}

\author{
Roshani S. Manekk ${ }^{1}$, Aditya Mehta ${ }^{2}$ \\ 1,2 Department of General Surgery, Jawaharlal Nehru Medical College, Datta Meghe Institute of \\ Medical Sciences (Deemed University), Sawangi (Meghe) Wardha, Maharashtra, India.
}

\section{INTRODUCTION}

Echinococcus granulosus is the most common cause of hydatid disease of the lung. Hydatid disease is endemic to the Mediterranean countries, Middle East, South America and Australia. After liver, lung is the $2^{\text {nd }}$ most common organ involved in this disease. ${ }^{1}$

The main route of infection is infestation of the embryo which after passing through the duodenal wall enters into the portal vein or the peri duodenal and perigastric lymphatics. The pulmonary cysts develop through this route, secondary to hepatic lesions. ${ }^{1}$ Pulmonary hydatidosis is most commonly seen in men during the $2^{\text {nd }}$ and $3^{\text {rd }}$ decades of life.

An intact cyst can be defined as "simple or closed cyst", and a ruptured and / or infected cyst" can be defined as "complicated cyst". 2 Recurrence has been defined as new active cysts appearing after therapy, which includes reappearance with continual growth of live cysts at the site of a previously treated cyst or new distant disease appearing as a result of spillage. ${ }^{3}$ The diagnosis of hydatid cyst diagnosis is often delayed because patients are asymptomatic for years during the period of growth of the parasite. ${ }^{2}$ Surgical goals in a case of hydatid cyst are: A - total eradication of the parasite; $\mathrm{B}$ - the prevention of the cyst 's rupturing on the operative field and its consequent dissemination; and $\mathrm{C}$ - the extirpation of the residual cavity. ${ }^{4}$ In this article, we report a rare case of male patient with multiple daughter cysts in the left lung at pleura-parenchymal junction and mediastinum who presented to us with recurrent pulmonary hydatidosis, which has caused complication of expectoration of multiple daughter cyst of small size.

\section{PRESENTATION OF CASE}

A 32-year-male, farmer by occupation who rears sheep and goats for his livelihood, came with complaints of pain in the left side of the chest and back, pain since past 2 months. Patient also complained of cough and breathlessness since one and half month. Patient gave typical history of grape like material in the sputum twice in past 2 months. The patient gave no history of pain in abdomen, haemoptysis and fever. 10 years back, patient was diagnosed to have pulmonary hydatid cyst in the left lung for which patient underwent thoracotomy with excision of cyst. On examination there was left thoracotomy healthy scar over the left side of chest wall. On auscultation, there was absent air entry over the left side of the lung. On abdominal examination, there was no organomegaly.

X-ray chest revealed multiple cavities containing fluid on the left side. Right lung was normal (Fig. 1A and 1B). On high resolution computed tomography (HRCT) thorax there was evidence of well-defined multiloculated, peripherally enhancing fluid filled cystic lesions with multiple internal septations, noted along the mediastinal, coastal pleura and lung parenchyma. Few cystic lesions showed water lily sign, with collapse of left lower lobe. (Fig. 2)
Corresponding Author: Dr. Aditya Mehta,

Department of General Surgery, Jawaharlal Nehru Medical College, Datta Meghe Institute of Medical Sciences (Deemed to Be University), Sawangi (Meghe) Wardha, Maharashtra, India. E-mail: dr.adityamehta@gmail.com

DOI: $10.14260 / j e m d s / 2021 / 160$

How to Cite This Article: Manekk RS, Mehta A. Recurrence of primary pulmonary hydatidosis in the left lung with no hepatic involvement. J Evolution Med Dent Sci 2021;10(10):746-748, DOI: 10.14260/jemds/2021/160

Submission 05-11-2020,

Peer Review 08-01-2021,

Acceptance 16-01-2021,

Published 08-03-2021.

Copyright (C) 2021 Roshani S. Manekk et al. This is an open access article distributed under Creative Commons Attribution License [Attribution 4.0 International (CC BY 4.0)] 

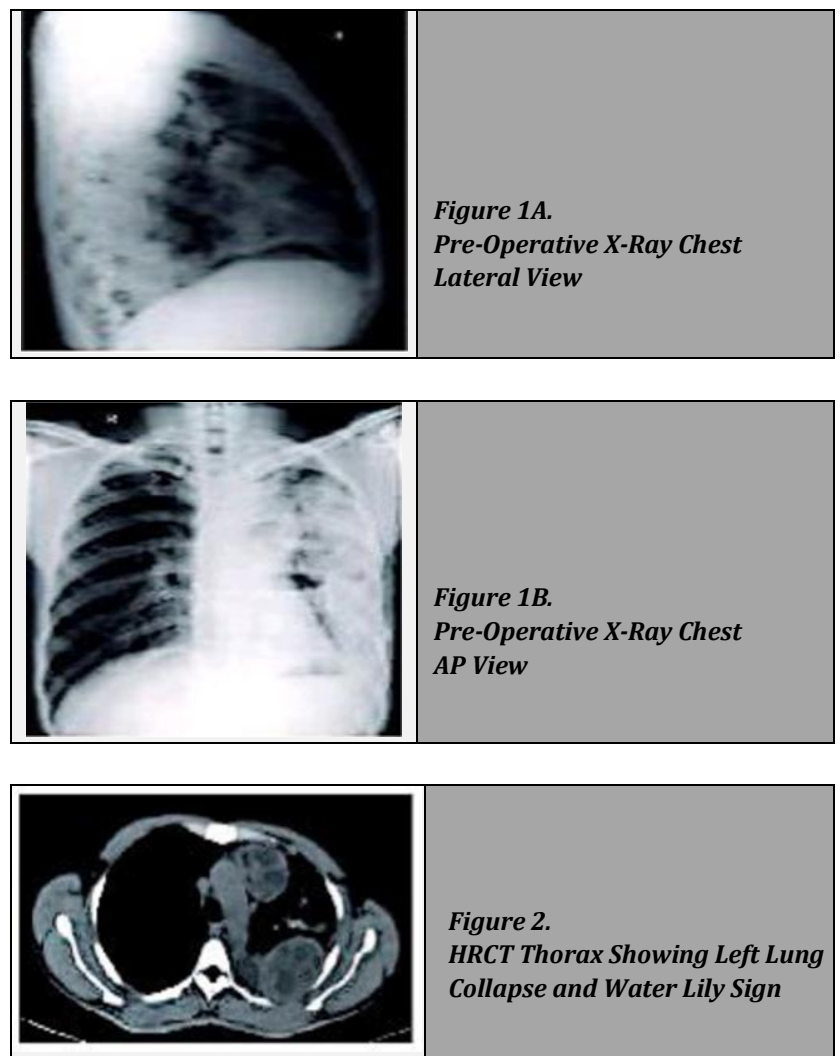

Figure 2.

HRCT Thorax Showing Left Lung Collapse and Water Lily Sign

\section{DISCUSSION OF MANAGEMENT}

Routine lab investigations were done along with pulmonary function test. Patient was operated under general anaesthesia and intubated using double lumen endotracheal tube. Incision was taken over the $5^{\text {th }}$ intercoastal space at the site of previous scar. Due to the presence of dense adhesions between the chest wall and the cyst wall (Fig. 3A and 3B), the cyst got ruptured on incision and cystic fluid filled with laminated membrane were aspirated. Multiple multiloculated daughter cysts varying from size of $2 \mathrm{~mm}$ to $40 \mathrm{~mm}$ were identified in the fluid (Fig. 3B).

On exploration the cyst was found to be extending from the apex of the lung up to the diaphragm involving the pericardial space. The cavity was irrigated with betadine solution. The places where the thickened pleura was adhered with lung and pericardium was carefully separated and excised, thereby releasing the pulmonary parenchyma leading to expansion of the lung. The thoracotomy was closed after placing an implantable cardioverter-defibrillators (ICD) in situ. Patient recovered well and ICD was removed on post-operative day (POD) 5 with suture removal on day 10 . Chest $x$ ray (CXR) done on POD 1 showed thickened pleura and and expanding left lung. On POD 12 CXR showed clearance of haze on left side (Fig. 3C). Patient was discharged on tab albendazole 400mg BD for 6 weeks.

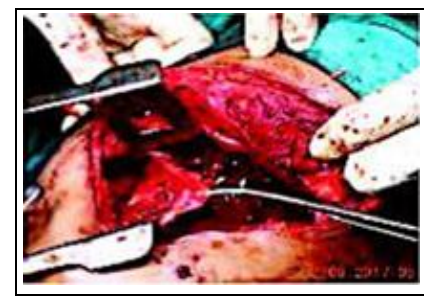

Figure $3 A$.

Shows Multiple Lobules of the Cyst with Adhesions to the Pleura and Pericardium
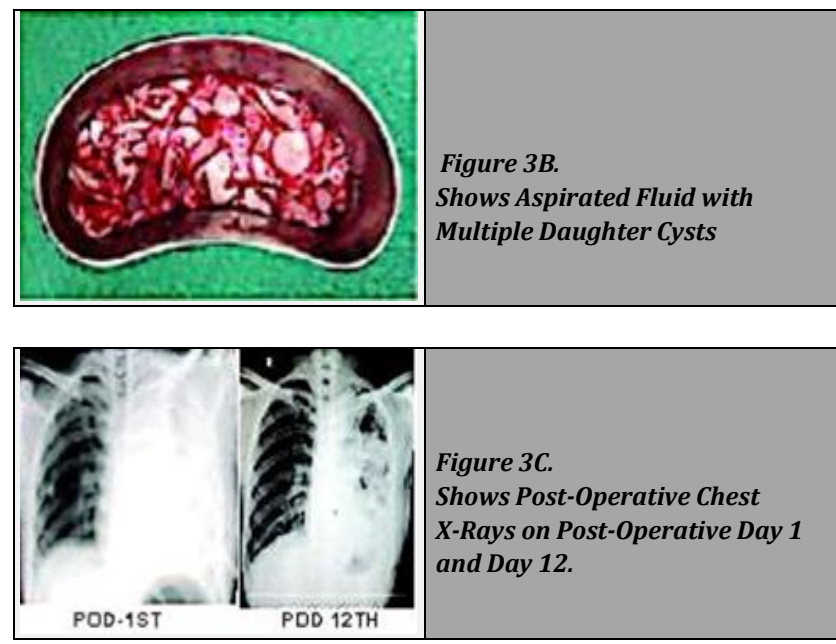

\section{DISCUSSION}

A study by Shalabi et al. (2002) suggests that, hydatid diseases are found in the sheep-raising countries such as, South America, Australia, Greece and Middle Eastern countries. ${ }^{5}$ Another study suggests that the, incidence of hydatid disease can be seen at any age and sex, with predominance in age group of $20-40$ yrs. $^{6}$

A study by Kervancioglu, $\mathrm{R}$ et al. mentions that when the cyst ruptures the most common symptoms are chest pain, fever, dyspnoea, cough, expectoration and haemoptysis. The expectoration of the membrane and / or hydatid sand is suggestive of a ruptured cyst and is used as a diagnostic indicator for hydatid disease. ${ }^{2}$ Another study by Morar. R et al. suggest, a contained rupture means that, only the endocyst is torn and the cyst contents are enclosed in the pericyst. ${ }^{6}$ In the present case the patient presented with cough, left sides chest pain, breathlessness and expectoration of grape like material in the sputum suggestive of a contained ruptured cyst.

Aytaç A et al. in their study mention that, pulmonary hydatid cysts can involve any pulmonary lobe and can be made up of multiple foci in one or both lungs. The most frequently affected area of the lung is the right lower lobe. ${ }^{1}$ Chest $x$-rays which display oval or spherical masses in the lung fields are diagnostic of hydatid lung disease. ${ }^{1}$

Morar. R et al. study mentions that the right lung is affected in $60 \%$ of cases of pulmonary hydatid disease. The plain chest $\mathrm{x}$-ray is the most valuable diagnostic method for hydatid lung disease. ${ }^{6}$ The study also describes that, computed tomography (CT) scan can depict the cystic nature of the lung mass as well as it can provide accurate localisation. This helps in planning of surgical treatment of complicated cysts. The crumpled endocyst floats freely in the cyst fluid, when it has completely collapsed (water-lily sign or Camelotte sign). ${ }^{6}$

Ayuso. A et al. show in their study that, bypassing through the liver, the embryo can reach the lung via the lymph ducts and recently it has been demonstrated that the disease can also be contracted via the bronchi. ${ }^{4}$ In the present case study there are 2 peculiar features seen, firstly there is primary involvement of the lung parenchyma with no involvement of the liver, secondly only left lung involvement can be appreciated. Also x-ray chest was done which revealed multiple cavities containing fluid on the left side. Right side of 
the lung was normal, and the HRCT showed presence of water lily sign in few cysts.

Shalabi et al. (2002) in his study mentions that, surgical removal of pulmonary hydatidosis along with maximum preservation of the parenchyma of lung is the main stay of treatment. ${ }^{5}$ A study shows that, whether symptoms are present or not, all hydatid lung cysts should be surgically treated when diagnosed to prevent complications. ${ }^{7}$ Another study mentions that albendazole trial alone is reasonable, in patients having recurrent disease, especially if not used previously. Its use in recurrent disease has not been extensively studied. ${ }^{8}$ In this case surgical excision of the cyst was done with release of dense pleural adhesions and post operatively patient was discharged on tab albendazole $400 \mathrm{mg}$ BD for 6 weeks.

\section{FINAL DIAGNOSIS}

Pulmonary hydatidosis in the left lung.

\section{CONCLUSIONS}

We conclude that despite the type of presentation in a case of pulmonary hydatidosis, surgical management with complete excision of cyst and removal of cystic contents remains the mainstay of treatment. The benefits of albendazole therapy pre- and post-surgery in a case of complicated and uncomplicated hydatid cyst, needs further studies to decrease the recurrence of hydatid disease.

Financial or other competing interests: None.

Disclosure forms provided by the authors are available with the full text of this article at jemds.com.

\section{REFERENCES}

[1] Aytaç A, Yurdakul Y, Ikizler C, et al. Pulmonary hydatid disease: report of 100 patients. Ann Thorac Surg 1977;23(2):145-51.

[2] Kervancioĝlu R, Bayram M, Elbeyli L. CT findings in pulmonary hydatid disease. Acta Radiol 1999;40(5):51014.

[3] Prousalidis J, Kosmidis C, Anthimidis G, et al. Postoperative recurrence of cystic hydatidosis. Can J Surg 2012;55(1):15-20.

[4] Ayuso A, Peralta T, Lazaro B, et al. Surgical treatment of pulmonary hydatidosis. J Thorac Cardiovasc Surg 1981;82(4):569-75.

[5] Shalabi RI, Ayed AK, Amin M. 15 years in surgical management of pulmonary hydatidosis. Ann Thorac Cardiovasc Surg 2002;8(3):131-4.

[6] Morar R, Feldman C. Pulmonary echinococcosis. Eur Respir J 2003;21(6):1069-77.

[7] Kuzucu A, Soysal Ö, Özgel M, et al. Complicated hydatid cysts of the lung: clinical and therapeutic issues. Ann Thorac Surg 2004;77(4):1200-4.

[8] Sielaff TD, Taylor B, Langer B. Recurrence of hydatid disease. World J Surg 2001;25(1):83-6. 